\title{
THE DECOMPOSITION OF BROMOFORM
}

BY GEORGE J. SARGENT

E. D. Campbell ${ }^{1}$ made some bars of annealed crucible steel, containing r.29 percent carbon, anode in a 4 percent hydrochloric acid solution. A weak current was passed through the solution. After fifteen or sixteen hours the bars were removed, the adhering residue brushed off, and then placed in a fresh solution and the process repeated. The residues were collected and washed by decantation. Only the heavier particles were allowed to settle.

The result was a heavy, bright, steel-gray powder which appeared, under the microscope, as thin plates or scales. Its carbon and its iron content agreed quite well with the formula $\mathrm{Fe}_{3} \mathrm{C}$. By alternately moistening and then drying in an air bath at a temperature of about $70^{\circ} \mathrm{C}$ for six weeks, it was slowly but completely oxidized to $\mathrm{Fe}_{2} \mathrm{O}_{3}$. The carbide was practically completely soluble in moderately concentrated hydrochloric acid, with the evolution of hydrogen and hydrocarbon of the paraffin and olefine series. Campbell found that the paraffin hydrocarbons consisted almost entirely of ethane, and the olefine hydrocarbons principally of ethylene and butylene with some dibutylene.

To quote Campbell: "As early as 1864, Hahn," and, again in 1877 , Cloez ${ }^{3}$ showed, by dissolving cast irons in dilute hydrochloric or sulphuric acid, that a portion of the carbon passed off with the hydrogen as ethylene, $\mathrm{C}_{2} \mathrm{H}_{4}$, propylene, $\mathrm{C}_{3} \mathrm{H}_{6}$, butylene, $\mathrm{C}_{4} \mathrm{H}_{8}$, and dibutylene, $\mathrm{C}_{8} \mathrm{H}_{14}$. This they showed by passing the gas through bromine and purifying and fractionally distilling the dibrom derivatives thus obtained.

"At the time of Hahn's and Cloez's work no definite

${ }^{1}$ Jour. Am. Chem. Soc., I8, 836 (I896).

${ }^{2}$ Liebig's Ann., I29, 57 (1864).

${ }^{8}$ Compces rendus, 85, 1003 ( 1877 ). 
carbide of iron had been isolated, and no possible explanation offered for presence of the gaseous products of solution of a mixture of hydrogen, olefins and paraffins. We would recall two well-known facts before offering a possible explanation for the composition of the gas evolved in dissolving iron containing carbon. The first of these is the tendency of the olefine with the general formula $\mathrm{C}_{n} \mathrm{H}_{2 n}$, to combine with nascent hydrogen to form the corresponding paraffins, $\mathrm{C}_{n} \mathrm{H}_{2 n+2}$, and also the tendency of some of the higher olefines, especially butylene, $\mathrm{C}_{4} \mathrm{H}_{8}$, and those of a higher molecular weight to form condensation products.

"It would seem not unreasonable to assume that iron is capable of forming a series of what we might properly term ferro-carbons analogous to the olefine series of hydrocarbons; that this series has the general formula $\mathrm{C}_{n} \mathrm{Fe}_{3 n}$, in which the group - $\mathrm{Fe}-\mathrm{Fe}-\mathrm{Fe}-$ replaces $\mathrm{H}_{2}$ in the olefine series, $\mathrm{C}_{n} \mathrm{H}_{2 n}$; that, when these ferro-carbons are acted upon by an acid, such as hydrochloric or sulphuric acid, the first reaction is the substitution of two hydrogen atoms for the two iron atoms, thus producing the analogous olefine, $\mathrm{C}_{n} \mathrm{H}_{2 n}$, free hydrogen being liberated between the iron atoms. Thus, the primary products of solution of these ferro-carbons would be olefines, $\mathrm{C}_{n} \mathrm{H}_{2 n}$, and hydrogen, but, owing to the tendency of the olefines to combine with nascent hydrogen, the secondary reaction producing a greater or less proportion of paraffins would take place.

"That this is probably the case is rendered the more probable from the fact that the proportion of paraffins to olefines varies somewhat with varying conditions of solution. The first reaction in the case of the simplest of these ferrocarbons, $\mathrm{C}_{2} \mathrm{Fe}_{6}$, when dissolved in hydrochloric acid, is as follows :

$$
\mathrm{C}_{2} \mathrm{Fe}_{6}+{ }_{12} \mathrm{HCl}=\mathrm{C}_{2} \mathrm{H}_{4}+\mathrm{FeCl}_{2}+{ }_{4} \mathrm{H}_{2} \text {. }
$$

Or the reaction may be represented graphically as follows: 


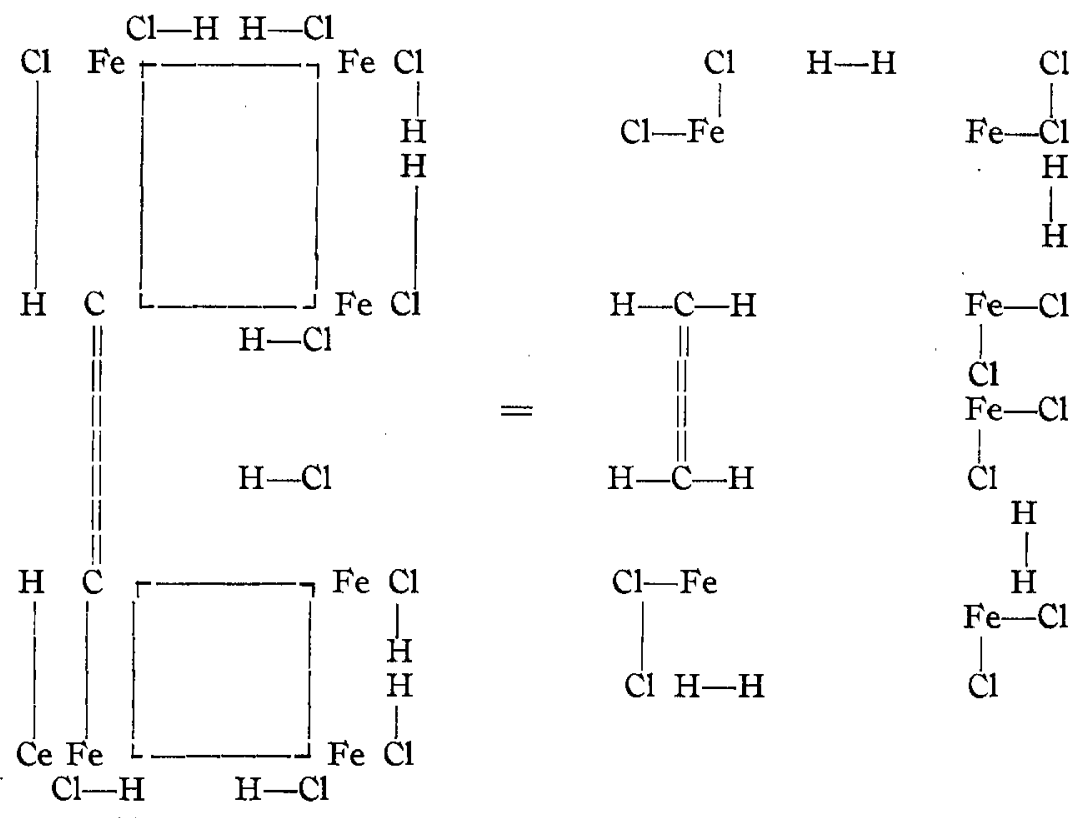

"The secondary reaction between hydrogen and the olefines would be one of direct addition to form the homologous paraffins."

Campbell's assumed structure of the hypothetical series of ferro-carbons has the defect, that while the first member of the series $\mathrm{C}_{2} \mathrm{Fe}_{6}, \mathrm{Fe}-\mathrm{Fe} \mathrm{Fe}-\mathrm{Fe}$ on treatment with acids<smiles></smiles>

would give $\mathrm{H}_{2} \mathrm{C}=\mathrm{CH}_{2}$, the second member of the series $\mathrm{C}_{3} \mathrm{Fe}_{9}$,

would give

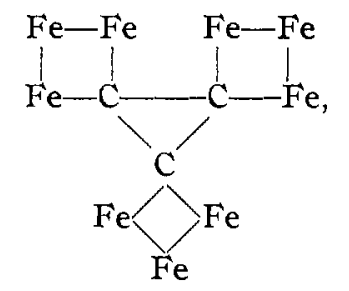<smiles>C1CC1</smiles> 
trimethylene, not propylene. The third member of the series, $\mathrm{C}_{4} \mathrm{Fe}_{12}$, would give<smiles>C1CCC1</smiles>

tetramethylene, not butylene.

The work of Gladstone and Tribe ${ }^{1}$ on the decomposition of chloroform, bromoform, and iodoform by the zinc-copper couple seemed at least to suggest a simpler explanation for the composition of the gas evolved when iron containing carbon is dissolved in acids.

Gladstone and Tribe used a zinc-copper couple prepared by treating some well-crumpled zinc foil with a dilute copper sulphate solution, whereby the zinc becomes coated with a deposit of copper. The couple was then washed and dried. It was found to have no appreciable action on chloroform either alone or in the presence of ether.

Gladstone and Tribe used a solution of $5 \mathrm{cc}$ ( 7.5 grams) of chloroform dissolved in 20 cc of absolute alcohol. The action of the couple on this solution began at a temperature . of about $50^{\circ} \mathrm{C}$. The reaction was represented by the equations

$$
\mathrm{CHCl}_{3}+\underset{2}{3 \mathrm{CHCl}_{3} \mathrm{C}_{2} \mathrm{H}_{5} \mathrm{OH}+3 \mathrm{Zn}=\mathrm{C}_{2} \mathrm{H}_{2}+3 \mathrm{CH}_{4}+\mathrm{ZnCl}_{2}}
$$

The reactions ran nearly to completion. A yield of I. 7 percent acetylene meant that $\mathrm{I} .7$ percent of the total chloroform in the solution was decomposed to form acetylene.

A moist couple acted on chloroform at ordinary temperatures according to the equation

$$
{ }_{2} \mathrm{CHCl}_{3}+3 \mathrm{H}_{2} \mathrm{O}+6 \mathrm{Zn}={ }_{2} \mathrm{CH}_{4}+{ }_{3} \mathrm{Zn}_{2} \mathrm{OCl}_{2} \text {. }
$$

The action of the couple on a bromoform solution consisting of $2.5 \mathrm{cc}$ ( 7 grams) bromoform in $20 \mathrm{cc}$ of absolute alcohol was very rapid at room temperatures. A yield of I9 percent acetylene was obtained. The reaction ran nearly

${ }^{1}$ Jour. Chem. Soc., 28, 508 (1875). 
to completion as shown by the amount of zinc and bromine in solution, yet the amount of $\mathrm{C}_{2} \mathrm{H}_{2}$ and $\mathrm{CH}_{4}$ obtained accounted for only slightly over one-half of the bromoform. When zinc foil was substituted for the couple, the action at $50^{\circ} \mathrm{C}$ was slight, but fairly rapid at $60^{\circ} \mathrm{C}$. The yield of acetylene was greatly decreased being only $\mathbf{I} .73$ percent, also there was little loss of any of the $\mathrm{CH}$ of the bromoform. At ordinary temperatures the action of the moist couple on bromoform was very slow, methane being evolved; at $60^{\circ} \mathrm{C}$ a little acetylene was found mixed with the methane.

The action of the couple on an alcoholic solution of iodoform was extremely slow at ordinary temperatures, probably due to the slight solubility of the iodoform. In one experiment 8.45 grams of iodoform and ro cc of absolute alcohol were added to the couple and the whole heated to $40^{\circ} \mathrm{C}$. A yield of 27.4 percent of acetylene was obtained. There was a very considerable loss of the $\mathrm{CH}$ of the iodoform. When zinc foil was substituted for the couple, a yield of only I5 percent of acetylene was obtained. The loss of $\mathrm{CH}$ was far less than with the couple. Gladstone and Tribe thought that the loss of $\mathrm{CH}$ might be due to the formation of benzene, but tests gave only negative results. It was then thought that copper acetylide might have been formed on the surface of the copper in the couple. Accordingly the couple at the end of the reaction was washed with alcohol, then with water, dried and burned with copper oxide. An amount of carbon dioxide closely corresponding to the loss of $\mathrm{CH}$ was obtained. Thinking that a greater yield of acetylene would be obtained by substituting platinum for the copper of the couple, since acetylene was not known to combine with platinum, a zincplatinum couple was used. The action of this couple on an alcoholic solution of iodoform was more energetic than that of the zinc-copper couple. The yield of acetylene was about the same as that obtained when the zinc-copper couple was used. The loss of $\mathrm{CH}$ was also very nearly the same.

The following research was undertaken to determine whether the yield of acetylene could be appreciably varied 
by varying the concentration of the reacting solution. Bromoform was selected in preference to chloroform owing to the greater yield of acetylene, and in preference to iodoform owing to the limited solubility of the latter in alcohol. Since difficulty was experienced in the preparation of the zinccopper couple by the method of Gladstone and Tribe, the method proposed by Lachman ${ }^{1}$ was used, with a slight modification. A mixture of 12 parts of cupric oxide and 88 parts of zinc dust was heated in a combustion tube to dull redness for twenty minutes, with a streain of dry hydrogen passing through. In order to obtain as uniform a couple as possible, a considerable amount of the couple was prepared and mixed by shaking as uniformly as possible. It was noticed in some preliminary experiments, that the couple after some time appeared less active. This was believed to be due to a slow oxidation of the zinc by the oxygen of the air. To prevent this as far as possible the couple was kept in a flask in an atmosphere of hydrogen. In all the experiments the same amount of the couple was used, namely, is grams. It is recognized, however, that the use of the same amount ${ }^{-}$of couple in each experiment does not ensure that the same extent of surface of the sample is in contact with the bromoform solution.

The decomposition of the bromoform was carried on in a flask with a capacity of about $60 \mathrm{cc}$ fitted with a threeholed rubber stopper. Through one hole was introduced a thermometer, through another the tip of a burette, and through the third hole a capillary tube which connected the flask with a gas storage pipette. Owing to the solubility of acetylene in water or even in a salt solution, the gases were collected over mercury.

As it was usually necessary to heat the bromoform solution, especially the more dilute ones, in order to start the reaction and often necessary to cool them after the reaction had started, the decomposition flask was suspended in a beaker of water. By heating the water the contents

${ }^{1}$ Am. Chem. Jour., 19, 4 10 (1897). 
of the flask could be heated and it was also possible to run cold water in and out of the beaker, thus cooling the contents of the flask.

In making a determination fifteen grams of the couple were placed in the decomposition flask and the air in the apparatus replaced by dried hydrogen. The gas storage pipette was filled with mercury and the pressure of the hydrogen in the flask, which was above atmospheric pressure, was brought to the latter pressure by turning the burette stopcock quickly. The bromoform solution was then placed in the burette and run into the flask. The hydrogen displaced by the solution passed into the storage pipette. The temperature of the contents of the decomposition flask was raised if necessary to start the reaction and was kept as near $35^{\circ} \mathrm{C}$ as possible. This was usually very difficult if not impossible; however the temperature was somewhere within the limits of $30^{\circ}$ and $40^{\circ}$, save in exceptional cases. The pressure in the flask during the reaction was kept slightly below atmospheric pressure. In this way, in the unlikely case of slight leaks, no methane or acetylene would be lost and any air leaking in except in excessive amounts would have no influence on the results. After a sufficient amount of gas had been evolved, by which time the reaction took place only very slowly, the bromoform solution was cooled to room temperatures. This practically caused the reaction to stop. Absolute alcohol was now run in by means of the burette until all the gas in the flask was displaced. The gas in the storage pipette was analyzed in two portions. In the first portion the methane was determined; in the second the acetylene was determined.

To determine the methane a known amount of the gas was passed into a pipette containing an ammoniacal cuprous chloride solution, then into a pipette containing potassium hydroxide, and finally into a pipette containing concentrated sulphuric acid. The gas now consisted of hydrogen, methane, bromoform vapor, and traces of alcohol vapor. This gas was passed into a combustion pipette and the hydrogen and 
methane determined. The amount of hydrogen in the apparatus at the start could be found by adding the volume of the bromoform solution used and the volume of absolute alcohol added. If the hydrogen by the two methods agreed within the limits of experimental error the amount of alcoholic vapor mixed with the hydrogen, methane, and bromoform vapor must be slight. This was found to be the case.

It was found to be impossible to determine the acetylene by noting the decrease in volume of the gas in the ammoniacal cuprous chloride pipette as the contraction was far larger than the amount of acetylene present. At one time it was believed that formic aldehyde vapor was present because colored rings were obtained with resorcinol and also with gallic acid tests. However, blank tests in the presence of zinc bromide, alcohol and water gave similar results.

The second portion of gas was passed into a small flask containing ammoniacal cuprous chloride and the copper acetylide formed was filtered and washed, first with dilute ammonium hydroxide and then with water. The precipitate was partially decomposed by means of hot hydrochloric acid, the small amount undissolved was heated to decompose it into copper and carbon and the copper dissolved with a little nitric acid. The solution containing the copper from the copper acetylide was made slightly alkaline with sodium hydroxide and boiled in order to precipitate the hydrated cupric oxide. This precipitation was carried on in a porcelain dish to avoid contamination with silica. After filtration the precipitate was washed, dried, ignited and weighed. This method of determination gives slightly high results, due to the adsorption of sodium salts by the cupric oxide.

Acetylene is somewhat soluble in alcohol or bromoform, so that some acetylene remained in the solution in the decomposition flask. In order to determine the amount, the solution was filtered and washed once with alcohol. This operation was carried on as rapidly as possible to avoid loss of acetylene. The acetylene in the filtrate was distilled in a current of hydrogen and passed into some ammoniacal cuprous chloride solu- 
tion. Together with the copper acetylide, there was precipitated some nearly black substance which on ignition either volatilized or was oxidized. The copper in the copper acetylide was determined as before.

In the following tabulation of data:

$\mathrm{V}=$ volume of bromoform solution used

$V_{1}=$ volume of gas taken for the determination

$\mathrm{V}_{2}=$ volume of gas from the absorption pipettes

$\mathrm{V}_{3}=$ volume of oxygen added plus $\mathrm{V}_{2}$

$\mathrm{V}_{4}=$ volume after combustion

$\mathrm{V}_{5}=$ volume of $\mathrm{CO}_{2}=$ volume of $\mathrm{CH}_{4}$

$\mathrm{V}_{6}=$ total volume of $\mathrm{CH}_{4}$, corrected

$\mathrm{V}_{7}=$ total volume of $\mathrm{C}_{2} \mathrm{H}_{2}$, corrected

$\mathrm{H}=$ height of the barometer in millimeters

$\mathrm{T}=$ room temperature

$\mathrm{W}_{1}=$ weight of $\mathrm{CuO}$ corresponding to the acetylene in the gas evolved.

$\mathrm{W}_{2}=$ weight of $\mathrm{CuO}$ corresponding to the acetylene dissolved in the solution. By percent acetylene is meant the volume of acetylene in the total $\mathrm{CH}_{4}+\mathrm{C}_{2} \mathrm{H}_{4}$ found.

The solution first used was solution $\mathrm{A}$, which consisted of one part by weight of bromoform and four parts by weight of absolute alcohol. Appreciable action of the couple on this solution began at about $20^{\circ} \mathrm{C}$. At a temperature of $35^{\circ} \mathrm{C}$, the action was fairly rapid for a short time, then becoming rather slow.

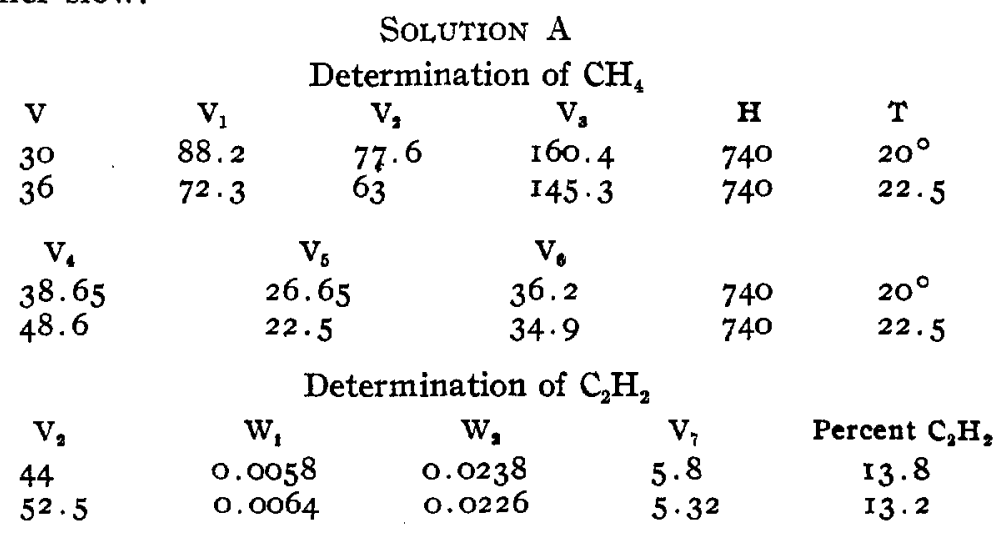

The solution next used consisted of one part of bromoform and three parts of absolute alcohol. 


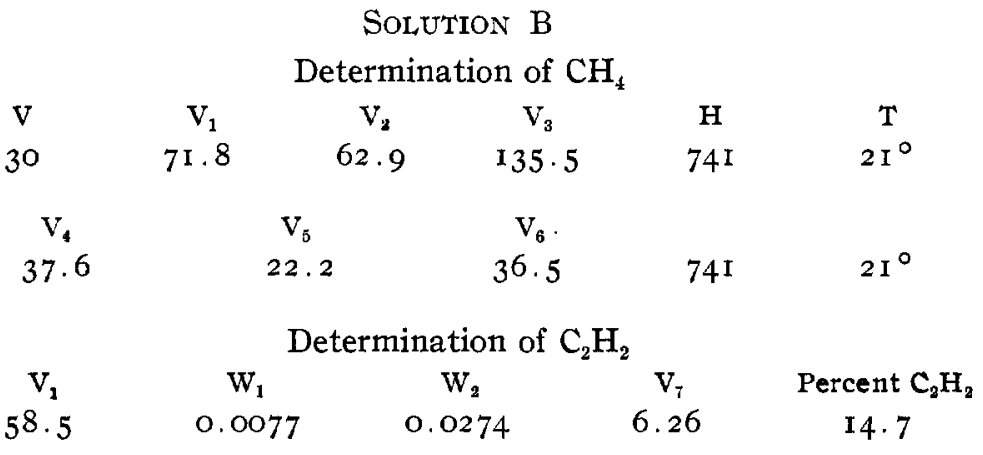

As only a small increase of acetylene was found, a much stronger solution was used. Solution $C$ consisted of four parts of bromoform and five parts of absolute alcohol.

An appreciable reaction of the couple on this solution began as low as $15^{\circ} \mathrm{C}$ and in a short time became very violent. The decomposition flask was cooled immediately the reaction began but it was very difficult to keep the temperature of the contents of the flask below $40^{\circ}$ until after the violence of the reaction had decreased considerably.

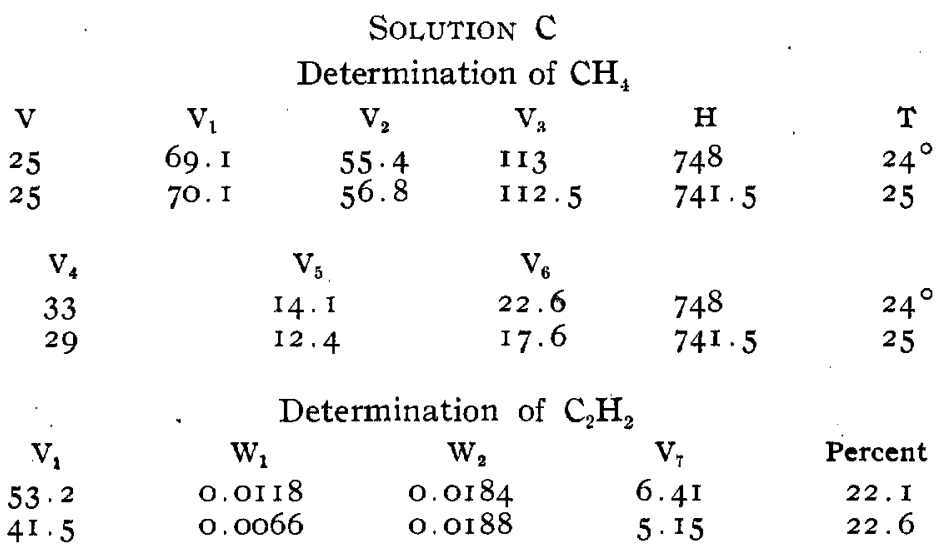

These results show an increase of about 9 percent acetylene as compared with those obtained with solution A. By using more concentrated solutions of bromoform without doubt far greater yields of acetylene would be obtained. Stronger 
solutions were not used owing to the violence of the reaction which made temperature regulation very difficult.

The influence of water on the yield of acetylene was next investigated. Solution D consisted of one part bromoform, one part of water, and four parts of absolute alcohol.

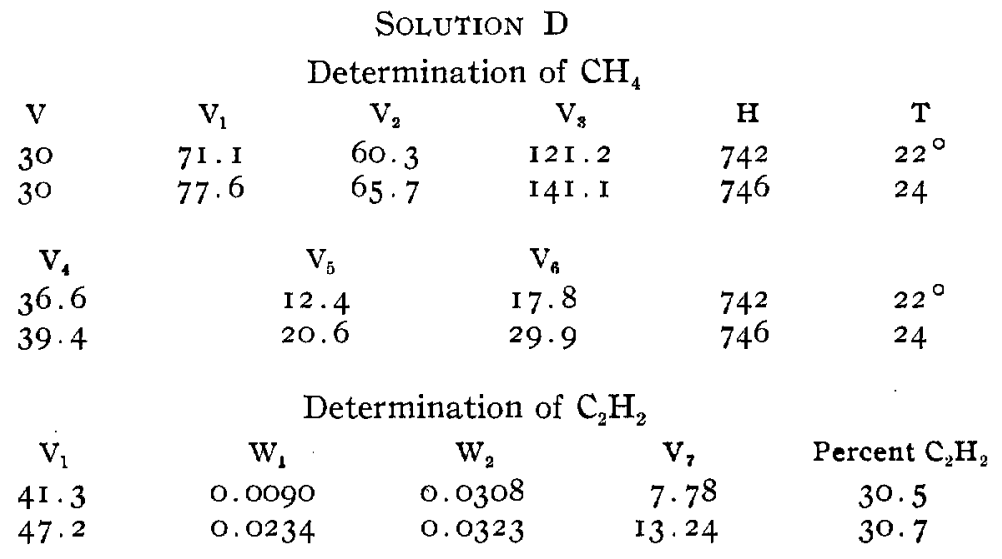

The addition of an amount of water equal to the amount of bromoform to solution A considerably more than doubles the yield of acetylene. This result was rather unexpected as Gladstone and Tribe state, regarding the action of the zinc-copper couple on bromoform in the presence of water: "At ordinary temperature, action takes place very slowly, methane being evolved and zinc bromide and oxybromide formed. At $60^{\circ}$ the action is, of course, more rapid and the methane is found mixed with a little acetylene."

Since the couple acts on water with the evolution of hydrogen while with absolute alcohol there is no appreciable reaction it might be thought that water added to the bromoform solution would tend to reduce the $\mathrm{CH}$ to $\mathrm{CH}_{4}$ with a greater yield of methane. On the other hand, when water and alcohol are mixed there is an evolution of heat and, therefore, the alcohol would probably be in a more stable state. Water added to a mixture of bromoform and alcohol causes the bromoform to be less soluble, and, therefore, the 
bromoform is in a less stable state. Accordingly, a greater yield of acetylene in the presence of water might be expected.

In order to determine whether the increase of acetylene was due to the specific nature of the water, an equal amount of benzene was substituted for the water. Solution $\mathrm{E}$ consisted of one part of bromoform, and one part of benzene, and four parts of absolute alcohol. The benzene vapor in the gas evolved was removed by passing the gas into a pipette containing an ammoniacal solution of nickel cyanide.

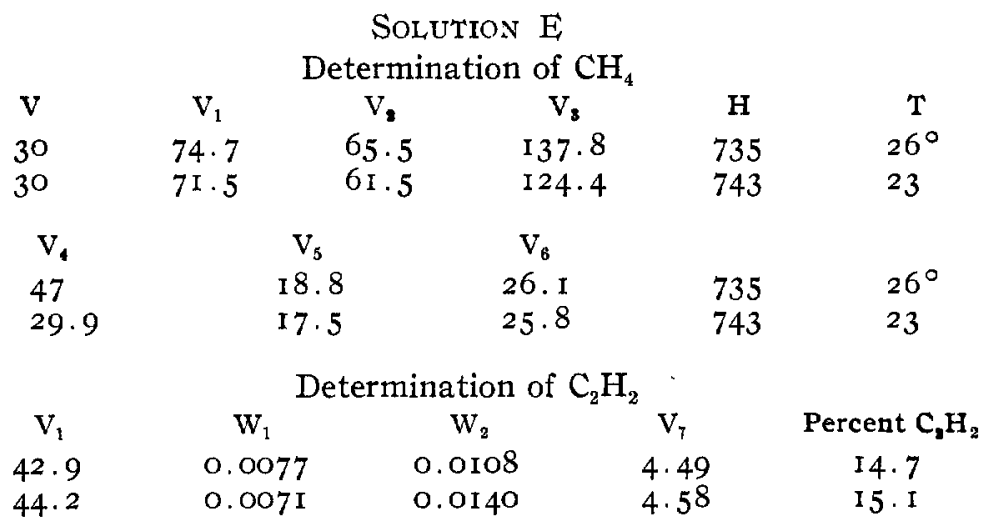

These results are somewhat higher than those obtained with solution $A$ but easily show that the increased yield of acetylene in the presence of water was due to the specific nature of the water. Further proof of this is given by the work of Cazeneuve ${ }^{1}$ who obtained good yields of acetylene by adding bromoform and a solution of $\mathrm{CuCl}_{2}$ to zinc dust. The resulting zinc-copper couple decomposes the bromoform. It seems rather strange, in view of this, that Gladstone and Tribe obtained only a little acetylene mixed with the methane.

The action of zinc-copper couples prepared by different methods is quite probably not exactly the same. Gladstone and Tribe obtained very much less acetylene by the decomposition of bromoform by means of zinc foil than by means of the zinc-copper couple. It is evident that a couple containing

\footnotetext{
${ }^{1}$ Comptes rendus, 97, I37 I (1883).
} 
one amount of zinc would act somewhat differently from a couple containing a different amount of zinc.

It is quite possible that Gladstone and Tribe's loss of $\mathrm{CH}$ was partially or even wholly due to acetylene remaining behind dissolved in the decomposition solution. They say nothing of this possibility or of any boiling of the solution which would remove dissolved acetylene.

Berthelot, in 1866 , found that on heating pure acetylene in a curved tube over mercury to a temperature sufficient to soften hard glass, the volume of the gas decreased and at the same time tarry products made their appearance. In one experiment, 97 percent of the original acetylene had disappeared, leaving only 3 percent unchanged, while almost all the carbon and hydrogen of the acetylene were found in the liquid and solid products of the reaction. These latter consisted of various polymers of acetylene, such as benzene, which was the chief product, styrolene, etc.

Iron carbide is not the only carbide yielding more than one hydrocarbon on decomposition. Moissan prepared $\mathrm{CeC}_{2}$, $\mathrm{LaC}_{2}, \mathrm{YtC}_{2}$, and $\mathrm{ThC}_{2}$, which are decomposed by water, giving mixtures of acetylene and methane. Moissan also prepared the definite well-crystallized compound $\mathrm{Ur}_{2} \mathrm{C}_{3}$, which, on decomposition by water, not only gives a gaseous mixture of methane, acetylene, and hydrogen, but also amounts of liquid and solid hydrocarbons corresponding to two-thirds of the carbon contained in the carbide. In accordance with Campbell's view of this behavior, it would seem necessary to assume the existence of several series of uranium carbides. All these uranium carbides would have to be isomorphous and be present in such amounts as to give uranium and carbon contents agreeing with the formula $\mathrm{Ur}_{2} \mathrm{C}_{3}$.

To account for the products ethane, ethylene, butylene, and dibutylene, which are obtained by the decomposition of iron carbide by hydrochloric acid, Campbell believed it not unreasonable to assume the existence of a series of ferrocarbons analogous to the olefine series of hydrocarbons. Yet here is a carbide, $\mathrm{CHBr}_{3}$, which on decomposition gives 
the direct products methane and acetylene in varying amounts depending on the conditions, and the indirect products benzene, styrolene and naphthalene. It is not necessary or even possible to assume the existence of a series of bromoforms in order to account for the products obtained by the decomposition of bromoform. This being the case, it appears unnecessary to assume the existence of a series of ferro-carbons analogous to the olefine series of hydrocarbons, especially in the absence of anything directly tending to prove their existence.

A simpler and, at present, apparently more probable explanation for the products obtained by the decomposition of iron carbide by hydrochloric acid, is that the first product of the decomposition are hydrogen, ferrous chloride and $\mathrm{CH}_{2}$. This $\mathrm{CH}_{2}$ is liberated in the so-called nascent state and in the very probable presence of catalytic agents. It is also incapable of existing alone. Under these conditions it polymerizes into $\mathrm{C}_{2} \mathrm{H}_{4}, \mathrm{C}_{3} \mathrm{H}_{8}, \mathrm{C}_{8} \mathrm{H}_{8}$, etc.

Some of the $\mathrm{C}_{2} \mathrm{H}_{4}$ formed is reduced to $\mathrm{C}_{2} \mathrm{H}_{0}$. The above explanation for the products of the decomposition of iron carbide seems also applicable to the products obtained by the decomposition by water of the carbides $\mathrm{CeC}_{2}$, and $\mathrm{LaC}_{2}, \mathrm{YfC}_{2}$, $\mathrm{ThC}_{2}$ and $\mathrm{Ur}_{2} \mathrm{C}_{3}$. In the case of bromoform, we evidently have $\mathrm{CH}$ set free which polymerizes to $\mathrm{C}_{2} \mathrm{H}_{2}$ or is reduced to $\mathrm{CH}_{4}$, depending on the conditions of the experiment. Special experiments would be necessary to show whether, or how, the iron carbides could be decomposed so as to yield methane or acetylene as the chief gaseous products. This interesting problem does not come within the scope of this investigation which merely proves that it is not safe to deduce the molecular weight of a carbide from its hydrocarbon decomposition products.

This investigation was undertaken at the suggestion of Professor Bancroft, to whom the author is greatly indebted for the many very valuable suggestions given during the research.

Cornell University 